가톨릭대학교 의과대학 여의도 성모병원 내과학교실

노은숙, 박민경, 안지원, 이승재, 손혜숙, 성혜영, 최선욱, 김길선, 형복진, 이상훈, 김용현, 송정섭

\title{
A Case of Pulmonary Cryptococcosis in an Immunocompetent Patient
}

Eun Suk Roh, M.D., Min Kyung Park, M.D., Ji Won An, M.D., Seung Jae Lee, M.D., Hye Suk Son, M.D., Hye Young Sung, M.D., Son Ook Choi, M.D., Guil Sun Kim, M.D., Bok Jin Hyoung, M.D., Sang Hun Lee, M.D., Yong Hyun Kim, M.D., Jeong Sup Song, M.D.

Department of Internal Medicine, St. Mary's Hospital, The Catholic University of Korea, College of medicine, Seoul, Korea

We experienced a case of pulmonary cryptococcosis in an immunocompetent patient who presented with uncommon radiological findings. He complained of a dry cough for 3 weeks. The chest X-ray and CT showed multiple, variable sized, and irregular patch consolidations with cavities combined with some ground glass opacities in both lower lung fields. The diagnosis was made histologically via a thoracoscopic lung biopsy. The patient was administered oral fluconazole has since been well. (Tuberc Respir Dis 2005; 59: 700-704)

Key words : Cryptococcosis, Immunocompetent patient, Multiple cavities

서 론 고하는 바이다.

폐 효모균은 비전염성의 기회감염 혹은 불현성 감 염을 일으키는데 특히 비둘기나 닭의 분비물에 오염 된 토양에 존재하며 호흡기를 통해 인체에 들어와 주 로 폐, 중추신경계, 피부 등에 침범하여 전신 질환을 일으킨다.

면역기능이 결핍된 환자에서 수막염을 동반한 파 종성의 효모균 감염은 임상적으로 흔하나 면역기능 이 정상인 사람에서도 비파종성의 감염을 볼 수 있으 며 이러한 경우 효모균 감염은 방사선학적으로 단일 의 폐결절, 경화 혹은 종격동의 종괴 형태로 발현하는 폐감염 증례들이 우리나라에서는 보고 되었다 ${ }^{1-3}$.

저자들은 기침을 주소로 내원한 면역 기능이 정상 인 19세 남자에서 양 폐야에 다발성 경화와 불규칙적 인 결절, 공동화의 방사선학적 소견을 보이는 폐 효모 균증의 1 례를 경험하였기에 문헌고찰과 함께 이에 보

Address for correspondence : Jeong Sup Song, M.D. Department of Internal Medicine, St. Mary's Hospital The Catholic University of Korea, 62, Yeouido-dong, YoungdungPo-gu Seoul, 150-713, Korea

Phone : 82-2-3779-1102 Fax : 82-2-786-1518

E-mail : jssong@catholic.ac.kr

Received : Aug. 22. 2005

Accepted : Sep. 21. 2005

\section{증 례}

환 자 : 홍○민, 19세 남자

주 소 : 3 주 동안의 마른 기침

현병력 : 환자는 평소 건강하였던 자로 내원 3 주 전부터의 기침을 주소로 개인 의원을 방문하여 시행 한 단순 흉부 촬영에서 양쪽 폐 하엽에 다발성 경화 와 결절의 소견이 관찰되어 전원 되었다.

과거력 및 사회력,가족력 : 과거력상 환자는 비흡 연자인 학생으로 특기할 만한 질환은 없었으며, 가족 력상에서도 특기할만한 사항은 없었다.

이학적 소견 : 환자의 전신상태 및 영양상태는 양 호하였다. 혈압은 $130 / 60 \mathrm{mmHg}$, 맥박 85회/분, 호흡 수 13 회/분이었으며, 체온은 $37^{\circ} \mathrm{C}$ 이었다. 환자의 피 부 및 두부 이학적 검사에서 이상이 없었고, 경부 임 파절은 촉지 되지 않았다. 흥부 청진시 양쪽 하엽에서 기관지 호흡음과 흡기시 수포음이 들렸다. 심음은 정 상이었고 기타 부위의 진찰상 특이 소견은 없었다.

검사실 소견 : 말초혈액검사에서 백혈구 12800 $/ \mathrm{mm}^{3}$ (호중구 $76.4 \%$, 림프구 $13.9 \%$, 호산구 $1.9 \%$ ), 혈 색소 $12.2 \mathrm{~g} / \mathrm{dL}$, 혈소판은 $135 \times 10^{9} / \mathrm{L}$, 적혈구 침강속도 는 $32 \mathrm{~mm} / \mathrm{h}, \mathrm{CRP} 7.8 \mathrm{mg} / \mathrm{L}$, 뇨분석과 전해질 검사는 


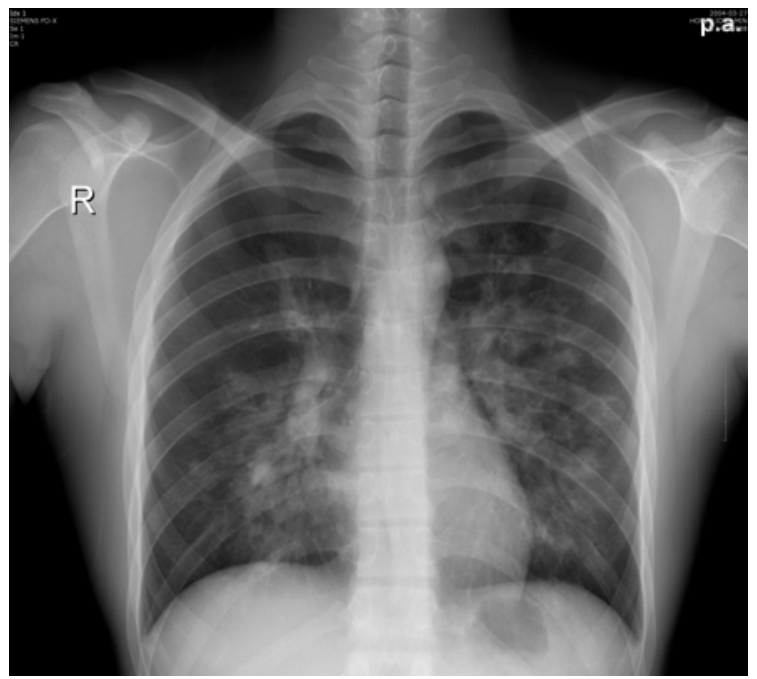

Figure 1. Chest X-ray shows multiple pathy consolidations with or without cavities in both central lung zones.
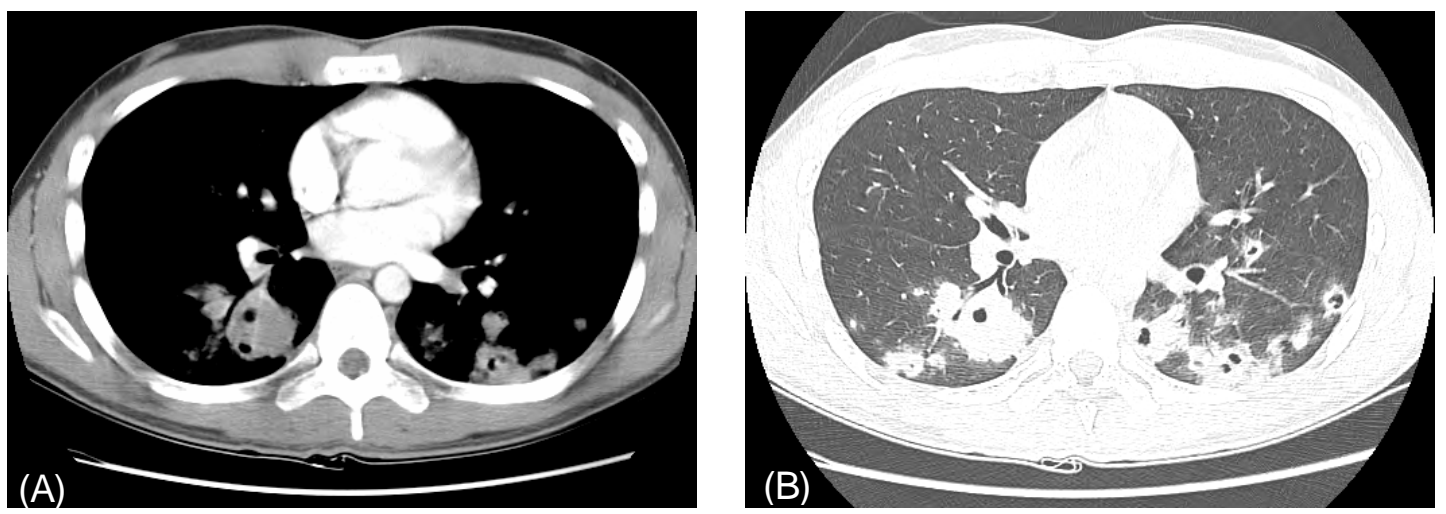

Figure 2. Chest CT shows multiple, variable sized, irregular patchy consolidations with or without cavities in both lung fields. The lesions are prominent in both lower lobes(A). Some ground glass opacities, micronodules, and branching linear structures are also seen (B).
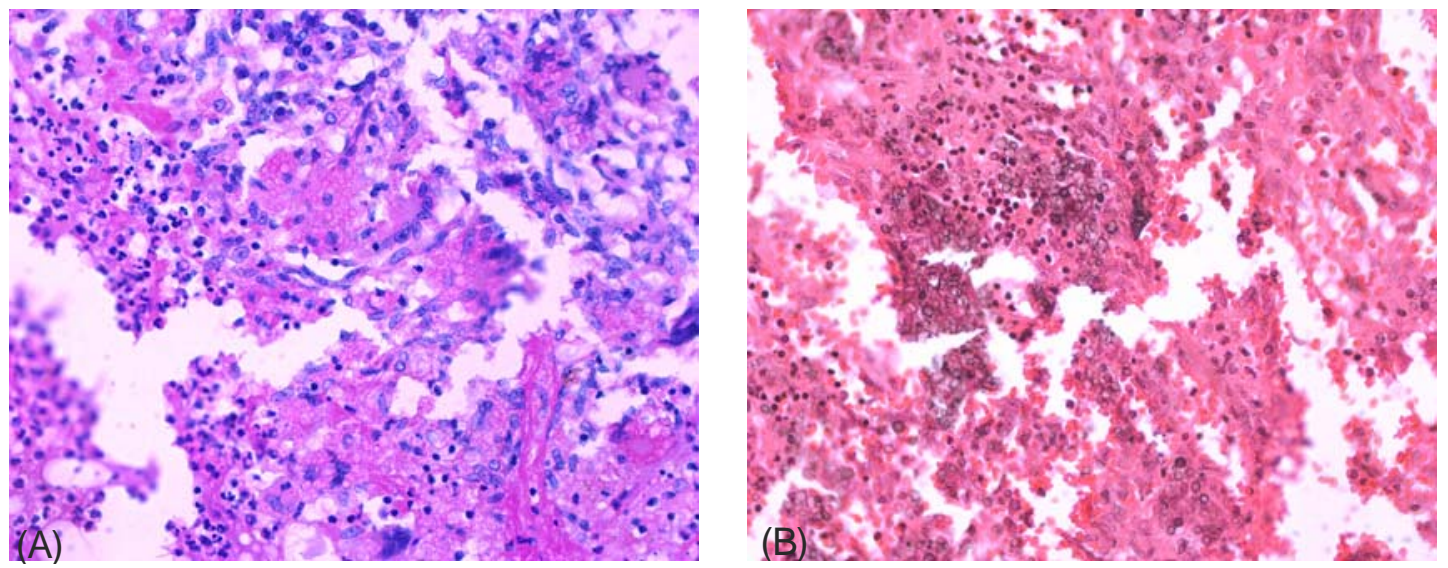

Figure 3. Microscopic findings showing cryptococcal yeasts with capsular polysaccharides stained intense red with periodic acid-Schiff(A) and mucicarmine(B) ( PAS stain, mucicarmine stain $\times 400$ ). 
나 기관지내 협착 혹은 종물은 관찰되지 않았다. 기관 지 세척액의 세포진 검사, 항산성 염색, 진균 도말 및 그람염색, India ink 염색, Ziehl-Neelson 염색 결과는 모두 음성이었다. 세균과 진균 배양 검사 역시 음성이 었다.

병리학적 소견 : 흥강 내시경하 절제된 쐐기 모양 의 조직편은 $4.0 \times 1.5 \mathrm{~cm}$ 으로 폐 실질은 부드러우면서 갈색을 나타냈으며 광학 현미경 관찰상 곰팡이 포자 를 포함하고 있는 거대세포들이 모인 육아종성 염증 반응이 보여 특수 염색(methenamine silver stain, Periodic acid Shiff stain)을 시행한 결과 양성 소견 보여(Figure $3 \mathrm{~A}, 3 \mathrm{~B}$ ) 효모균증으로 진단하였다.

임상경과 : 현재 환자는 fluconazole을 경구 복용 하며 외래에서 추적 관찰하는 중으로 임상 증상 및 방사선학적 소견은 호전되었다.

\section{고 찰}

효모균은 토양에 존재하며 4-6 $\mu \mathrm{m}$ 크기를 가진 효 모양 진균으로 7종으로 분류되며, 이중 Cryptococcus neoformans (C. neoformans)가 주로 질병을 일으키며 병원성이 약한 Cryptococcus albus도 사람에게 질병 을 일으키는 것으로 알려져 있다. C. neoformans는 다당체 피막의 항원성에 따라 혈청형 $\mathrm{A}, \mathrm{B}, \mathrm{C}, \mathrm{D}$ 가 있고 주로 $\mathrm{A}, \mathrm{D}$ 에 의해 감염증이 나타난다. C. neoformans는 주로 호흡기를 통하여 감염이 이루어지며, 체내의 전파는 혈행성으로 일어나나 드물게는 림프 계를 통해서도 전파되며 침범 장기는 뇌, 척수막이 가 장 흔하고 폐와 피부 그 밖의 거의 모든 장기에의 침 범이 가능하다 5 .

효모균증은 모든 연령에서 발생하나 35-50세에 호 발하며 폐장 효모균증은 모든 효모균증의 약 $10 \%$ 를 차지한다. 원발성 폐감염의 예는 1924년 Sheppe에 의 해 처음으로 보고 되었으며, 그 이후에는 진단 방법의 제한으로 보고가 거의 없었다. 1968년 Tynes 등과 Warr등이 적절한 방법으로 객담에서 배양이 가능하 고 기도의 집락균일 가능성이 더 많다고 보고하였으 며, Centers for Disease Control(CDC)에서 다기관 연구를 통해 폐침윤이 없는 집락화의 개념이 성립하
였다. C. neoformans의 조직 침윤을 통한 폐 감염증 은 흔히 증상이 없다. 증상을 호소하는 환자에서는 기 침(54\%), 흥통(46\%), 객담(32\%), 체중감소(26\%), 미 열(26\%), 객혈(18\%), 전신쇠약, 식욕부진 등의 증세 가 생긴다고 한다.

방사선학적 소견을 보면 단순흉부사진 소견으로 Khoury ${ }^{7}$ 등이 24명의 폐 효모균증 환자를 대상으로 한 연구에서 면역기능이 정상인 경우는 단발성 또는 다발성의 주변부 결절이 가장 흔한 소견(89\%)이며, 면역결핍이 동반된 경우에는 결절과 분절성 경화 (60\%), 양측성 기관지 폐렴양( $27 \%)$ 등의 다양한 형 태를 보이는데 임파절 종대, 공동형성, 늑막 삼출 등 도 잘 동반 할 수 있다고 하였다. Gordonson ${ }^{8}$ 등은 폐 의 공동화는 약 $10 \%$ 정도에 발생할 수 있다고 보고 하였고, 이전의 보고에서는 공동화 병변은 매우 드물 다고 하였다. 주로 후천성 면역결핍증후군 환자를 대 상으로 이루어진 전산화 단층 촬영소견으로는 양측 폐야(주로 폐문부)에 간질상 음영과 내부에 공기 기 관지 음영을 가지는 분절성 폐포성 음영이 가장 흔한 소견이며, 불규칙한 경계의 다발성 결절(30\%), 임파 절 증대로 보고하였으며,9,10, $\mathrm{Lee}^{11}$ 등의 연구에서 면 역기능이 정상인 경우의 가장 흔한 소견은 다발성의 불규칙한 경계를 가지는 결절과 경화이고 대부분 주 변부에 병소가 위치하였으며 경화의 내부에는 공기기관지 음영이 관찰되었다. 그러나 본 증례의 면역기 능이 정상인 환자에서는 다발성의 불규칙한 경화와 결절 외에도 이전의 보고에서는 흔치 않았던 폐의 공 동화 병변이 양폐야에 다수 관찰되었다.

폐 조직의 육안 소견에서 가장 흔히 볼 수 있는 것 은 다양한 조직 반응을 동반하면서 폐 효모균이 국소 적으로 모여 있는 소견이며, 광학현미경하 관찰에서 폐포와 기도내에 피막을 가진 병원체의 증식을 볼 수 있다 ${ }^{5,12}$. 염증 반응의 정도는 염증 소견은 없으면서 병원체로 이루어진 종괴에서부터 페포내 육아종성 반응까지 다양하며, 후자의 경우 다핵형 거대 세포내 에서 종종 병원체를 발견할 수 있다.

정상인에서 폐 고립결절이 효모균증으로 의심되면 기관지 폐포 세척액의 배양, 효모균 항원 검사, india ink 검사를 우선 할 필요가 있고, 확진을 위해서는 기 
관지내시경을 통한 폐 생검 혹은 개흥 조직 검사를 시행한다. 광학현미경 검사에서는 균주를 증명하기 위해 India ink, papanicolau, methenamine silver, periodic acid-Schiff, mucicarmine 염색법이 사용되 는데, India ink 염색시 피막이 염색되지 않아 윤상으 로 나타난다. 감별 진단으로는 폐암으로 방사선 사진 상 종괴가 있을 때는 객담 배양에서 C. neoformans가 배양되어도 우선 폐암을 의심해야 한다. 그것은 만성 폐질환이 있는 환자의 $0.5-1 \%$ 에서 C. neoformans가 호흡기에 부패균으로 존재하기 때문이다. 그 외에 결 핵, 유육종, 기관지 확장증, 폐 농양, 진폐증 등과 감 별해야한다 ${ }^{13}$.

폐 효모균증의 치료는 침범부위와 환자 상태에 따 라서 다르다. 과거에는 수술적 절제와 Amphotericin $\mathrm{B}$ 의 사용이 치료방법이었으나 Kerkering 등은 정상 인에서 발병한 폐 효모균증에 대해 항진균제 치료가 반드시 필요한 것은 아니라고 하였으며, 현재는 폐 외 의 다른 병변이 없는 경우 fluconazole을 경구로 2-6 개월간 사용하는 것이 추천되고 있다,14. 본 증례에서 는 fluconazole 경구 투여 후 임상적, 방사선학적으로 호전되어 외래에서 추적관찰 중으로 현재까지 별다 른 문제없이 환자는 잘 지내고 있다. 예후에 영향을 미치는 인자로는 폐 외전파와 환자의 면역 기능 상태 가 중요하며, 일반적으로 질병이 국한되고 정상적인 면역기능을 가진 경우에는 약 3 개월간의 추후 관찰이 필요하다.

\section{요 약}

저자들은 면역 기능의 장애가 없는 건강한 성인남 자에게서 이전에 수 차례 보고 된 바 있는 단순한 고 립성 폐결절, 경화, 종격동 종괴의 방사선학적 소견이 아닌 양쪽폐야의 다발성의 결절 및 공동화를 동반한 경화의 흔치 않은 방사선 소견을 보이는 폐 효모균증 1 예를 문헌 고찰과 함께 보고하는 바이다.

\section{참 고 문 헌}

1. Park CS, Ahn SY, Lee SH, Hong WK, Kim SK. A case report of cryptococcus restricted within mediastinum. Korean J Medicine 1986; 30:567-73.

2. Kang HC, Jang GL, Jung JY, Kim KS. A case of pulmonary cryptococcosis. Korean J Medicine 1988;36: $139-46$.

3. Park JC, Kim HT, Jeung H, Park JH, Choi JH, Kim HT et al. Various Pulmonary Manifestations of the cryptococcal pneumoniae in the three immunocompetent patients. Tuberculosis and Respiratory diseases 2001;50:359-66.

4. The Korean society for microbiology. Opportunistic fungal infection. Medical biology; 1991.p.694

5. Mandell GL, Benett JE, Dolin R. Principle and practice of infectious disease. 4th ed. New york: Churchill livingstone, Inc.; 1995. p. 2331-40.

6. Lee MS, Woo JH. Pulmonary cryptococcosis. J of Infection 1998; 30:86-93.

7. Khoury MB, Godwin JD, Ravin CE, Gallis HA, Halvorsen RA. Thoracic cryptococcosis: Immunologic competence and radiologic appearance. Am J Roentgenol 1984;142:893-6.

8. Gordonson J, Birnbaum W, Jacobson G, Sargent EN. Pulmonary cryptococcosis. Radiology 1974;112:557-61.

9. Gal AA, Koss MN, Hawkins J, Evans S Einstein H. The pathology of pulmonary cryptococcal infection in the AIDS. Arch Pathol Lab Med 1986;110:502-8.

10. Sider L, Westcott MA. Pulmonary manifestations of cryptococcosis in patients with AIDS: CT features. J Thorac Imaging 1994;9:78-84.

11. Lee CY, Kim H, Kim JS, Kim H, Woo SK. HRCT finding of pulmonary cryptococcosis in immune competent patients. J Korean Radiol Soc 2001;44:167-71.

12. McDonnell JM, Hutchins GM. Pulmonary cryptococcosis. Hum Pathol 1985;16:121-8

13. Duperval R, Hermans PE, Brewer NS, Robert GD. Cryptococcosis with emphasis on the significance of isolation of Cryptococcus neoformans from the respiratory tract. Chest 1977;7:13-9.

14. Kerkering TM, Duma RJ, Ochi T, Osugi T, Kikui M, Takahashi H. Japanese summer-type hypersensitivity pneumonitis: Studies using Cryptococcus antigen. Clin Allergy 1982;12:343-54. 